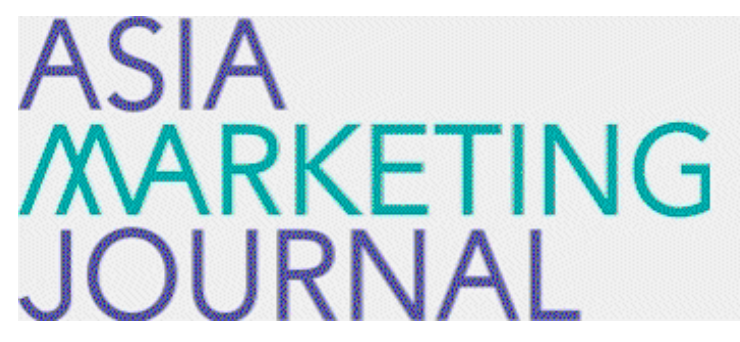

ASIA MARKETING JOURNAL

Volume 19 | Issue 2

Article 1

7-30-2017

\title{
Distinguishing Online Opinion Leaders
}

Yukyung Lee

Minjung Park

Subin Im

Follow this and additional works at: https://amj.kma.re.kr/journal

Part of the Marketing Commons

\section{Recommended Citation}

Lee, Yukyung; Park, Minjung; and Im, Subin (2017) "Distinguishing Online Opinion Leaders," Asia Marketing Journal: Vol. 19 : Iss. 2 , Article 1.

Available at: https://doi.org/10.15830/amj.2017.19.2.1

This Article is brought to you for free and open access by Asia Marketing Journal. It has been accepted for inclusion in Asia Marketing Journal by an authorized editor of Asia Marketing Journal. 


\title{
Distinguishing Online Opinion Leaders: The Mediating Effect of Consumer Innovativeness and Online Opinion Leadership for Values and New Product Adoption Behavior*
}

\author{
Yukyung Lee** \\ Minjung Park ${ }^{* * *}$ \\ Subin $\operatorname{Im}^{* * * *}$
}

This article empirically examines the relationship between values, consumer innovativeness, online opinion leadership, and new product adoption behavior utilizing wearable technology as the overall unit of analysis. The authors analyze data collected from SNS users who possess one or more wearable devices using a structural equation modeling approach to examine the direct effects. Moreover, a bootstrapping approach is adopted to explore the indirect effects between the constructs. The results indicate that consumers who value stimulation and hedonism are more inclined to possess stronger consumer innovativeness. Consumer innovativeness also positively influences online opinion leadership, ultimately leading to the faster adoption of new products. The mediating effect of consumer innovativeness between the value stimulation and online opinion leadership is also confirmed. In addition, although consumer innovativeness has no direct effect on new product adoption behavior, it does have an indirect, mediating effect through online opinion leadership.

Key words: wearable technology, Schwartz Value Survey, consumer innovativeness, online opinion leadership, new product adoption behavior

This work was supported by the BK21 Plus Grant given for Yonsei School of Business (Fostering Startup Professionals Based on Creativity, Entrepreneurship, and Sustainability).

** Graduate Student, Ewha Womans University Department of Clothing \& Textiles (irenep424@hotmail.com)

*** Associate Professor of Fashion Merchandising/Marketing, Ewha Womans University Department of Clothing \& Textiles (minjungpark@ewha.ac.kr)

***** Professor of Marketing, Yonsei University Yonsei School of Business (imsubin@yonsei.ac.kr), Corresponding Author 
The success of a new product largely rests on how enthusiastically it is embraced by its target audience immediately following its launch. Although companies adopt a number of different marketing methods, word-of-mouth [WOM] has been considered one of the most effective methods of customer acquisition (Villanueva, Yoo \& Hanssens 2008). Today, WOM often has shifted forms from physical interactions to online due to the increasing use of social media such as Facebook, Twitter, blogs, and other online channels (Berger \& Iyengar 2013; Dellarocas 2003; Schäfer \& Taddicken 2015). Online word-of-mouth, which is also known as electronic word-of-mouth [eWOM], is any comment made by past, present, and future customers regarding a product or company in an online platform or forum (Hennig-Thurau et al. 2004).

Opinion leaders are the epicenter of word of mouth information dissemination. They influence the information that other individuals interested in purchasing a new product receive (Vernette 2004). This influence now extends to the online environment. Schäfer and Taddicken (2015) note that today's opinion leaders operate in the online environment, referring to them as mediatized opinion leaders. Besides, opinion leaders have been shown to adopt new products faster than other consumers (Childers 1986; Flynn, Goldsmith \& Eastman 1996; Goldsmith \& De Witt 2003). Thus, to effectively disseminate information regarding new products to an audience, it is essential for firms to identify the characteristics of these opinion leaders if they are to be able to approach and target them effectively (Iyengar, Van den Bulte \& Valente 2011). Previous research by Im, Bayus, and Mason (2003) sought to discover innovative personal factors that lead to adoption of new consumer electronic products that were considered fairly new at the time of their research. The authors found that consumers' age and income as well as their innovative predispositions influence their new product adoption behavior. This study thus implies that the sophisticated innovative predispositions of consumers lead to new product adoption behavior by addressing their values as guiding principles of their behavioral patterns.

This study explores the factors that influence online opinion leadership and how it affects new product adoption behavior for new products. Wearable technology was chosen as the new product category for this study because it is currently undergoing rapid advances, with a continuous stream of new products being introduced to the public. Wearable technology refers to devices that provide personal experience across various activities via the Internet to those who wear them (Jellicorse 2015).

There are four major limitations within the current research stream. First, some researchers have determined that values are related to consumer innovativeness (Goldsmith, Heitmeyer \& Freiden 1991; Madrigal \& Kahle 1994; 
Rogers 1983; \& Scheufele 2006; Steenkamp \& Baumgartner 1992; Steenkamp, Hofstede \& Wedel 1999; Summers 1970) whereas other researchers have found positive relationships between innovativeness and opinion leadership (Grewal, Mehta \& Kardes 2000; Janjua \& Shahjahan 2015: Myers \& Robertson 1972; Ruvio \& Shoham 2007). However, there has been limited research that examined the mediating role of consumer innovativeness between values and opinion leadership. Second, although the relationships between innovativeness and opinion leadership (Grewal, Mehta \& Kardes 2000; Janjua \& Shahjahan 2015; Myers \& Robertson 1972; Ruvio \& Shoham 2007) and between opinion leadership and the actual innovative behavior (Childers 1986: Flynn, Goldsmith \& Eastman 1996; Goldsmith \& De Witt 2003) have been explored, to the best of our knowledge, few researchers have sought to verify the mediating effect of opinion leadership between consumer innovativeness and new product adoption behavior. Third, several studies have looked at online opinion leadership (Park 2013; Schäfer \& Taddicken 2015; Sun et al. 2006), but they represent an inchoate research stream that merely verifies the existence of opinion leaders in the online environment (Schäfer \& Taddicken 2015), with limited expansion on the diverse applications of opinion leaders (Park 2013; Sun et al. 2006). Finally, despite the growing attention it is receiving from both businesses and consumers, wearable technology has not been widely studied in academia. Thus, this paper attempts to address the following research questions:

1. Of the values that could potentially affect consumer innovativeness and online opinion leadership, which values influence the consumers' new product (wearable technology) adoption behavior?

2. Does consumer innovativeness have a mediating effect between values and online opinion leadership?

3. Does online opinion leadership have a mediating effect between consumer innovativeness and new product (wearable device) adoption behavior?

The objectives of this study are therefore to (1) identify the specific types of values that influence consumer innovativeness and online opinion leadership, and (2) empirically explore the relationships between values, consumer innovativeness, online opinion leadership, and new product adoption behavior. Both the direct and indirect relationships between the constructs are examined to verify the mediating effects of consumer innovativeness and online opinion leadership between values and new product adoption behavior. A structural equation model approach is adopted to investigate the direct effects; according to Anderson and Gerbing (1988). This approach facilitates the simultaneous exploration of the underlying relationships between multiple constructs (e.g., Im, Bayus 
\& Mason 2003, p. 62). A bootstrapping approach is then utilized to explore the indirect effects between the constructs, as recommended by Preacher \& Hayes 2008.

\section{Theoretical Background and Model Development}

\subsection{Defining Opinion Leadership}

Opinion leadership is defined as an individual's ability to influence others' attitudes or behaviors in a specific area (Grewal, Mehta \& Kardes 2000; Rogers 2003; Summers 1970). Ever since the 1950s, opinion leadership has consistently been the focus of attention for sociologists, especially in the United States. Early research conducted by Katz and Lazarsfeld (1955) provided the foundation for many follow-up studies of precisely how opinion leaders receive information and disseminate information to other individuals (as cited in Vernette 2004, p. 90). Overall, researchers consider opinion leaders a valuable media target because they are a quintessential source of information within various interpersonal communication contexts (Vernette 2004).

Opinion leadership research has primarily focused on the general opinion leaders who express their opinions face-to-face or via interpersonal media such as telephone calls, text messages, and e-mail (Flynn, Goldsmith \& Eastman 1996; Goldsmith \& De Witt 2003; Iyengar, Van den Bulte \& Valente 2011; King \& Summers 1970; Summers 1970), with little consideration of the role of the online opinion leaders who have emerged as important players due to the changing worldwide media environments (Schäfer \& Taddicken 2015). Schäfer and Taddicken argue that opinion leaders, who they refer to as mediatized opinion leaders, definitely exist in contemporary media environments, contending that compared to regular opinion leaders, mediatized opinion leaders exhibit a stronger usage of media and communication channels, including online media. These online opinion leaders share a propensity to disclose their thoughts and beliefs in a more honest and forthcoming way because of the greater anonymity offered by the Internet (Sun et al. 2006). While few studies have examined the direct relationship between the usage of social media and opinion leadership, several studies have supported the existence of a link between the two (Vraga et al. 2015). For example, Sun et al. (2006) measured online word-of-mouth with opinion leadership and opinion seeking in the online environment, while Park (2013) revealed the role of opinion leadership on Twitter in the political process. Based on the previous research, this study defines online opinion leadership as an individual's ability to influence others' attitudes or behaviors in some given topic area (Grewal, Mehta \& Kardes 2000; 
Rogers 2003; Summers 1970), particularly through online media (Schäfer \& Taddicken 2015).

This study draws upon the innovation diffusion theory conceptualized by Rogers (1995). The theory categorizes adopters of an innovation into five groups, namely innovators, early adopters, early majority, late majority, and laggards (Agarwal et al. 1998; Rogers 2002). Among these five groups, the early adopters are considered as the opinion leaders, who seek to persuade others of the benefits of adopting an innovation by providing a significant amount of information, tending to adopt and utilize innovations even when the consequences of doing so are highly uncertain (Agarwal et al. 1998).

\subsection{Research Model}

Based on innovation diffusion theory, it is evident that a deeper understanding of the characteristics of opinion leaders may be a useful tool for those seeking to promote the adoption of new products by the majority. In particular, understanding the traits of online opinion leaders is of critical importance because today's consumers are not only spending a significant amount of time online, but are also actively interacting with and being influenced by online opinion leaders. Hence, this study aims to empirically investigate the relationship between values, consumer innovativeness, online opinion leadership, and new product adoption behavior. Figure 1 demonstrates the conceptual model guiding this research.

\subsection{The Antecedents: Values (Stimulation, Hedonism and Achievement)}

This study centers on three value factors that are known to be antecedents to consumer innovativeness: stimulation, hedonism, and achievement. The Schwartz Value Survey (Schwartz 1992) utilized for the analysis is comprised of 57 single values representing 10

〈Figure 1〉 Conceptual Model of Hypothesized Relationships

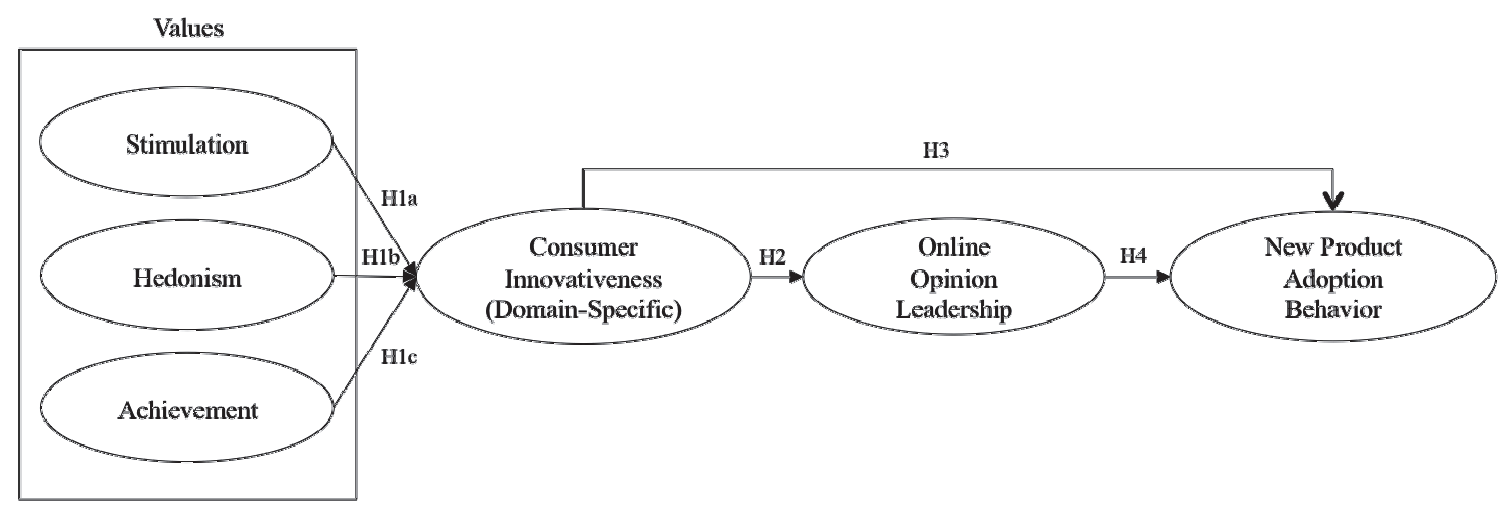


〈Figure 2〉 Theoretical Model of the Relationships Between Motivational Value Types, Higher Order Value Types, and Bipolar Value Dimensions (Schwartz 1992, p. 45)

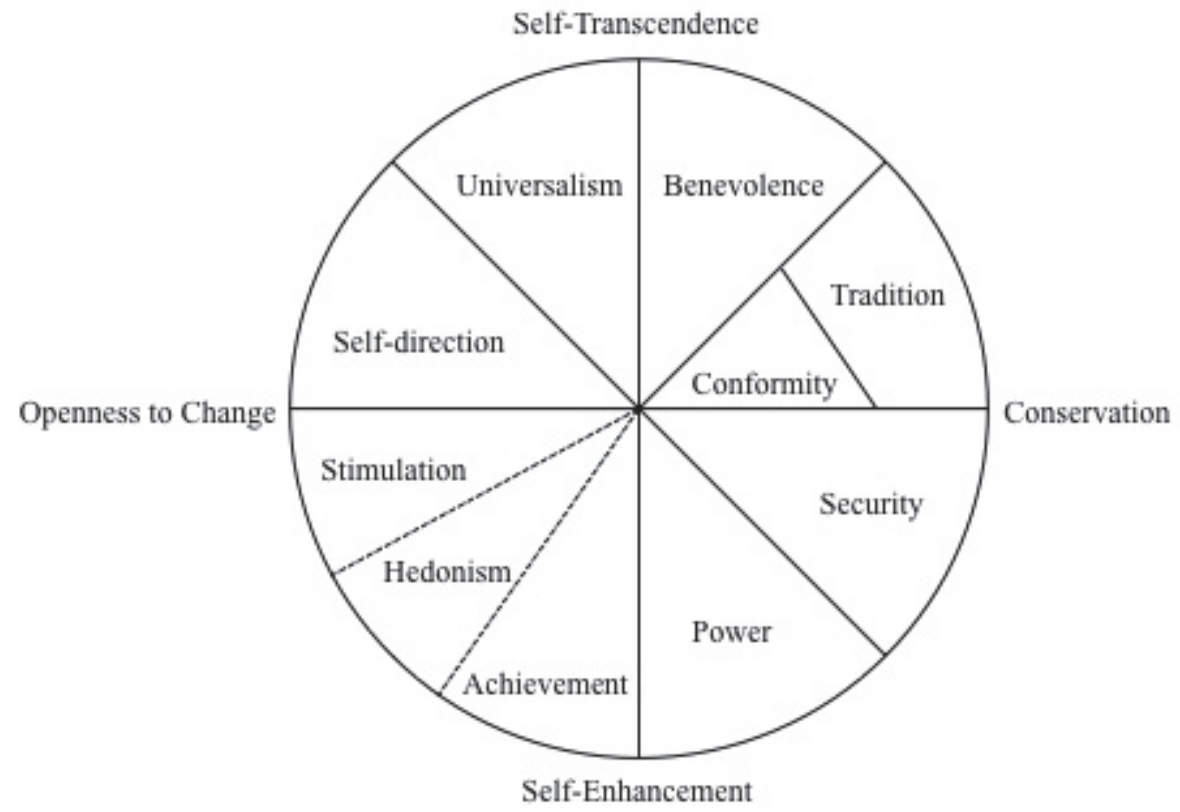

value types (Schwartz 1992). These 10 value types are themselves categorized into four broader and higher order types that compose two bipolar axes (Schwartz 1992). Interestingly, Schwartz organized these values into a circular structure (see Figure 2) that not only reveals the continuum between the value types, but also schematically represents the notion that these value types can be either consonant or dissonant, contingent upon the proximity of the value types (Steenkamp, Hofstede \& Wedel 1999; Kark \& Van Dijk 2007; Schwartz 1992). According to Williams (1979), these values tend to explain and influence human behavior as standards or criteria of conduct (as cited in Homer \& Kahle 1988, p. 638; Kamakura \&
Mazzon 1991, p. 208). In particular, various prior studies have revealed the correlation between values and innovative traits possessed by consumers (Rogers 1983; Steenkamp \& Baumgartner 1992; Steenkamp, Hofstede \& Wedel 1999; Peck \& Childers 2003; Cho \& Workman 2011).

Stimulation. Consistent with Schwartz (1996), we define stimulation as excitement, novelty, and challenge in life. Prior studies have revealed positive relationships between stimulation value and consumer innovativeness (Steenkamp \& Baumgartner 1992; Steenkamp, Hofstede \& Wedel 1999). Steenkamp and Baumgartner (1992) showed that the stimulation level positively correlates with innovativeness and 
involves an inclination to accept challenges and search for solutions to consumption issues. Steenkamp, Hofstede, and Wedel (1999) went on to demonstrate that resultant conservation - the term used by Feather (1995) to represent the increased weight that a consumer attributes to conservation compared to openness to change (as cited in Steenkamp, Hofstede \& Wedel 1999, p. 58) - has a negative effect on consumer innovativeness, which implies that personal value towards openness to change will have a positive effect on consumer innovativeness. Thus, our study anticipates the value stimulation to positively influence consumer innovativeness that is measured by domain-specific innovativeness. Stated formally,

H1a: People who value "stimulation" as the guiding principle in their lives possess stronger domain-specific innovativeness.

Hedonism. Hedonism is defined as seeking pleasure and sensuous gratification for oneself (Schwartz 1996). Prior researchers have examined the relationship between hedonism value and the innovative characteristics of consumers (Cho \& Workman 2011; Goldsmith, Heitmeyer \& Freiden 1991). Cho and Workman (2011) argue that consumers who possess fashion innovativeness tend to engage more in experiential shopping, which Peck and Childers (2003) argue is stimulated by an aspiration towards pleasure and sensory gratification. Furthermore, Goldsmith,
Heitmeyer and Freiden (1991) have verified positive relationships between fun and enjoyment and excitement values from Kahle's List of Values (1983) and fashion leadership. Hence, we expect the value hedonism to positively affect consumer innovativeness as measured by domain-specific innovativeness. Stated formally,

H1b: People who value "hedonism" as the guiding principle in their lives possess stronger domain-specific innovativeness.

Achievement. Achievement is defined as an individual's success gained by the display of his or her capability according to social standards (Schwartz 1996). A number of researchers have demonstrated a significant relationship between the achievement value and innovativeness of consumers (Madrigal \& Kahle 1994; Rogers 1983: Shah \& Scheufele 2006: Steenkamp, Hofstede \& Wedel 1999; Summers 1970). For example, Rogers (1983) claimed that early adopters tend to be higher in achievement motivation, rationality, ability, and intelligence (as cited in Steenkamp, Hofstede \& Wedel 1999, p. 56). Moreover, Steenkamp, Hofstede and Wedel had expected "resultant selfenhancement (i.e., the importance attached to self-enhancement minus the importance attached to self-transcendence; Feather 1995)" (1999, p. 58) to positively influence consumer innovativeness. This result proved to be insignificant, however: the authors discovered that consistent with 
their expectations, "the effect of resultant selfenhancement is smaller in absolute magnitude than the effect of resultant conservation $(\mathrm{p}<.01)$ " (Steenkamp, Hofstede \& Wedel 1999, p. 64). Therefore, we anticipate the value achievement to positively influence consumer innovativeness as measured by domain-specific innovativeness. Stated formally,

H1c: People who value "achievement" as the guiding principle in their lives possess stronger domain-specific innovativeness.

\subsection{The Mediating Effects: Domain- Specific Innovativeness and Online Opinion Leadership}

Innovativeness is defined as the degree to which any unit of adoption, such as an individual or organization, is comparatively faster in accepting new ideas than other members in the society (Goldsmith \& Hofacker 1991; Rogers 2002).

Innate innovativeness, which is also referred to as global innovativeness (Goldsmith, Freiden \& Eastman 1995), is an unobservable predisposition towards an innovation in a generalized way, which could be applied across different product categories (Im, Bayus \& Mason 2003). Thus, it can also be defined as the degree to which an individual can make certain self-reliant decisions without communicating with others (Goldsmith, Freiden \& Eastman 1995; Midgley
\& Dowling 1978).

Several researchers have pointed out that because innovativeness rarely overlaps between product categories (Gatignon \& Robertson 1985), examining the effects of innate innovativeness may be of no value for those curious about innovative tendencies within particular domains (Goldsmith \& Hofacker, 1991). For this reason, domain-specific innovativeness is measured instead in some studies. Goldsmith and Hofacker (1991) define domain-specific innovativeness as the propensity to embrace new products within a specific domain (Grewal, Mehta \& Kardes 2000). In this study, domain-specific innovativeness is utilized to measure consumer innovativeness, focusing specifically on the wearable technology product category. Aside from consumer innovativeness, both online opinion leadership and new product adoption behavior are also measured for wearable technology oriented scales.

Prior research in this area has revealed a significant relationship between innovativeness and opinion leadership (Grewal, Mehta \& Kardes 2000; Janjua \& Shahjahan 2015; Lyons \& Henderson 2005; Ruvio \& Shoham 2007). For instance, Grewal, Mehta and Kardes (2000) confirmed the positive influence of innovativeness on opinion leadership, while Ruvio and Shoham (2007) also found opinion leadership to be one of the outcome concepts arising from consumers' innovative tendencies. In terms of opinion leadership in the online 
environment, Lyons and Henderson (2005) demonstrated a significant positive relationship between opinion leadership in computer-mediated environments and innovativeness. Thus, we expect domain-specific innovativeness to positively influence online opinion leadership. Stated formally,

\section{H2: Consumers with domain-specific} innovativeness possess a higher level of online opinion leadership.

\subsection{The Outcome: New Product Adoption Behavior}

New product adoption behavior is defined as the actual adoption of novel information, ideas, and products; therefore, it can also be referred to as "actualized innovativeness" (Hirschman 1980). When defining new product adoption behavior, some researchers have focused on how fast the novel information, ideas, and products are actually acquired (Im, Bayus \& Mason 2003; Rogers \& Shoemaker 1971).

As explained earlier, wearable technology was chosen as the new product category for this empirical research study. However, notwithstanding the fact that wearable devices have been gaining the increasing popularity across the world, the number of people who possess them is by no means overwhelming and people owning more than one wearable device are few and far between. For this reason, it was not possible to utilize the "cross-sectional" method, which is simply counting the number of personal possessions in a certain product category at the time the survey is conducted (Im, Bayus \& Mason 2003; Midgley \& Dowling 1978; Rogers 1995). Instead, time of adoption was measured by counting the months between the new product's release date and the actual adoption date for each consumer as proposed by Midgley and Dowling (1978).

Consumer innovativeness and new product adoption behavior. In addition to the expectation that domain-specific innovativeness does indeed affect online opinion leadership, it seems likely that domain-specific innovativeness affects new product adoption behavior as well. Past studies appear to predict a significant positive relationship between domain-specific innovativeness and new product adoption behavior (Midgley \& Dowling 1978, 1993; Rogers \& Shoemaker 1971). For example, Midgley and Dowling (1993) discovered that "Innovative Communicators", whom prior researchers (Baumgarten 1975; Kotler \& Zaltman 1976) had regarded as a more quintessential consumer segment of diffusion than mere "innovators" or "opinion leaders" (as cited in Midgley \& Dowling 1993, p. 614), have shorter elapsed times to adoption across various innovations. Furthermore, Midgley and Dowling also drew attention to the operational definition of innovativeness proposed by Rogers and Shoemaker (1971), claiming that defining innovativeness in terms of "the degree to which 
an individual is relatively earlier in adopting an innovation than other members of his system" (Midgley \& Dowling 1978, p. 230) directly indicates a way to measure innovativeness, namely in terms of the time to consumers' actual adoption of products. It therefore seems likely that domain-specific innovativeness will positively influence new product adoption behavior. Stated formally,

\section{H3: Consumers with domain-specific} innovativeness are inclined to adopt new products faster than others.

Online opinion leadership and new product adoption behavior. Prior studies have revealed significant positive relationships between opinion leadership and the actual innovative behavior, which in this case is new product adoption (Childers 1986; Flynn, Goldsmith \& Eastman 1996; Goldsmith \& De Witt 2003). Flynn, Goldsmith, and Eastman (1996) emphasized the roles of opinion leaders as both information transmitters and first adopters (as cited in Goldsmith \& De Witt 2003, p. 28). In addition, Midgley and Dowling (1978) emphasized the role of the communication network created during the diffusion of innovation, contending that the network is a critical determinant of consumers' time of adoption. Hence, in this study online opinion leadership is postulated to positively influence new product adoption behavior. Stated formally,
H4: Consumers who possess a higher level of online opinion leadership will be inclined to adopt new products faster than others.

\section{Methods}

\subsection{Sample}

The survey data were obtained from the Macromill Embrain Company, Seoul, S. Korea. The study participants were owners of one or more wearable watches or bands who also used social network services. After deleting incomplete responses, a total of 206 complete and usable responses were available for the analysis. Table 1 presents the demographic information for the participants.

\subsection{Measures}

The measurement items are listed in full in Appendix A. The values of interest for this study (stimulation, hedonism, and achievement) were assessed using 3-item Likert-type scales (Schwartz 1992), as was the domain-specific innovativeness (Goldsmith, Freiden \& Eastman 1995). To measure online opinion leadership, a 4-item Likert-type scale was adapted from Huddleston, Ford and Bickle (1993) and modified to measure opinion leadership in the online 
〈Table 1〉 Descriptive Statistics for Demographic Variables

\begin{tabular}{|c|c|c|c|}
\hline Demographics & Items & $\mathrm{N}$ & $\%$ \\
\hline \multirow{3}{*}{ Gender } & Male & 104 & 50.5 \\
\hline & Female & 102 & 49.5 \\
\hline & Total & 206 & 100 \\
\hline \multirow{6}{*}{ Age } & $20 s$ & 86 & 41.7 \\
\hline & $30 \mathrm{~s}$ & 80 & 38.8 \\
\hline & $40 \mathrm{~s}$ & 29 & 14.1 \\
\hline & $50 \mathrm{~s}$ & 8 & 3.9 \\
\hline & $60 \mathrm{~s}$ & 3 & 1.5 \\
\hline & Total & 206 & 100 \\
\hline \multirow{5}{*}{ Education } & Under 6 years & 7 & 3.4 \\
\hline & 7-10 years & 150 & 72.8 \\
\hline & $11-15$ years & 37 & 18 \\
\hline & $16-20$ years & 12 & 5.8 \\
\hline & Total & 206 & 100 \\
\hline \multirow{5}{*}{ Monthly Income (KW) } & $1,000,000-4,900,000$ & 98 & 47.6 \\
\hline & $5,000,000-9,900,000$ & 87 & 42.2 \\
\hline & $10,000,000-14,900,000$ & 15 & 7.3 \\
\hline & Above 15,000,000 & 6 & 2.9 \\
\hline & Total & 206 & 100 \\
\hline \multirow{7}{*}{ Wearable Device Type } & Apple Watch Series & 31 & 15 \\
\hline & Samsung Gear Series & 104 & 50.5 \\
\hline & LG G Watch Series & 10 & 4.9 \\
\hline & Xiaomi Band Series & 36 & 17.5 \\
\hline & Fitbit Series & 18 & 8.7 \\
\hline & Others & 7 & 3.4 \\
\hline & Total & 206 & 100 \\
\hline
\end{tabular}

environment (Schäfer \& Taddicken 2015).

All measurement scales were verified for reliability and validity. In terms of reliability, Cronbach's alphas greater than .80 indicated that all the measures maintained good internal consistency (see Table 2). The confirmatory factor analysis performed to test the overall validity of the measurement scales revealed good convergent and discriminant validities for all the measurement scales. As recommended by Hair et al. (1998), all positive and significant factor loadings greater than .50 are considered to support significant convergent validity (as cited in Hunter 2010, p. 297). The t-values for 
〈Table 2〉 Cronbach's Alphas for All Construct Measures

\begin{tabular}{|c|c|c|}
\hline & Number of Items & Cronbach's $\alpha$ \\
\hline Stimulation & 3 & .87 \\
\hline Hedonism & 3 & .80 \\
\hline Achievement & 3 & .83 \\
\hline Domain-specific Innovativeness & 3 & .80 \\
\hline Online Opinion Leadership & 4 & .86 \\
\hline
\end{tabular}

all the items are above 1.97 and the values for composite reliability are above .70, thus also demonstrating good convergent validity. Following the recommendation of Anderson and Gerbing (1988), discriminant validity was tested by "examining whether the confidence interval around the correlation between any two latent constructs includes one" (as cited in Hunter 2010, p. 297); none of the confidence intervals includes one. The results of the confirmatory factor analysis are shown in Table 3, and the results of the exploratory factor analysis performed to confirm the unidimensionality of all the factors included in the value construct

〈Table 3〉 Confirmatory Factor Analysis Results for All Measurement Instruments ${ }^{\mathrm{a}}$

\begin{tabular}{|c|c|c|c|c|c|}
\hline Items & $\begin{array}{l}\text { Standardized Regression } \\
\text { Coefficient }\end{array}$ & $\mathrm{t}$-value & $\mathrm{P}$ & SMC & $\mathrm{CR}$ \\
\hline Stimulation 1 & .823 & & & .678 & \multirow{3}{*}{.829} \\
\hline Stimulation 2 & .886 & 14.002 & **** & .786 & \\
\hline Stimulation 3 & .793 & 12.538 & $* * *$ & .629 & \\
\hline Hedonism 1 & .740 & & & .548 & \multirow{3}{*}{.785} \\
\hline Hedonism 2 & .717 & 9.102 & $* * *$ & .514 & \\
\hline Hedonism 3 & .812 & 9.771 & $* * *$ & .660 & \\
\hline Achievement 1 & .864 & & & .747 & \multirow{3}{*}{.818} \\
\hline Achievement 2 & .785 & 11.867 & $* * *$ & .616 & \\
\hline Achievement 3 & .735 & 11.067 & **** & .540 & \\
\hline Domain-specific Innovativeness 1 & .768 & & & .589 & \multirow{3}{*}{.737} \\
\hline Domain-specific Innovativeness 2 & .820 & 9.500 & $* * *$ & .673 & \\
\hline Domain-specific Innovativeness 3 & .673 & 8.683 & **** & .453 & \\
\hline Online Opinion Leadership 1 & .676 & & & .458 & \multirow{4}{*}{.798} \\
\hline Online Opinion Leadership 2 & .825 & 9.980 & $* * *$ & .680 & \\
\hline Online Opinion Leadership 3 & .789 & 9.667 & $* * *$ & .622 & \\
\hline Online Opinion Leadership 4 & .804 & 9.802 & **** & .646 & \\
\hline
\end{tabular}


〈Table 4〉 Exploratory Factor Analysis Results for the Value Construct

\begin{tabular}{|c|c|c|c|}
\hline \multirow{2}{*}{ Items } & \multicolumn{3}{|c|}{ Factors } \\
\cline { 2 - 4 } & 1 & 2 & 3 \\
\hline Stimulation 1 & .883 & .189 & .19 \\
\hline Stimulation 2 & .839 & .243 & .157 \\
\hline Stimulation 3 & .799 & .293 & .153 \\
\hline Achievement 1 & .169 & .884 & .185 \\
\hline Achievement 2 & .248 & .818 & .114 \\
\hline Achievement 3 & .34 & .708 & .878 \\
\hline Hedonism 1 & .102 & .096 & .857 \\
\hline Hedonism 2 & .201 & .133 & .64 \\
\hline Hedonism 3 & .211 & .43 & \\
\hline
\end{tabular}

are presented in Table 4. Taken together, these results confirm that all measures maintain good convergent and discriminant validity, reliability, and unidimensionality.

The overall model's fit indices indicate a favorable model fit $\left(\chi^{2}=199.744\right.$, df $=105$, $p=.000$, Incremental Fit Index [IFI] $=.94 ;$ Tucker-Lewis Index [TLI] = .92; Comparative Fit Index $[\mathrm{CFI}]=.94$; root mean square error of approximation [RMSEA] $=.066)$, as shown in Table 3.

\section{Analysis and Results}

The connections in Figure 1 are empirically examined in two ways. First, the main effects between the constructs are examined to measure the direct effects (H1a, H1b, H1c, H2 to $\mathrm{H} 4$ in Figure 1) utilizing a structural equation model. The indirect effects between the constructs are then explored through bootstrapping, as recommended by Preacher and Hayes (2008).

\subsection{Main Effects}

This study was designed to assess the estimation of the coefficients of the model (H1a, H1b, H1c, H2 to H4 in Figure 1); all three factors of value (stimulation, hedonism, and achievement) were expected to influence domain-specific innovativeness. The results indicate that stimulation ( $\beta=.27, p=.007$ ) and hedonism $(\beta=.25, p=.036)$ are indeed significant at the .05 level, whereas achievement ( $\beta=-.05, p=.670)$ is insignificant. Thus, Hypotheses $1 \mathrm{a}$ and $1 \mathrm{~b}$ are supported, while Hypothesis 1c is rejected. Second, the domainspecific innovativeness was expected to have a positive effect on online opinion leadership. The estimation result reveals that this relationship 
is highly significant at the.001 level $(\beta=.39$, $p<.001$ ), so Hypothesis 2 is supported. Third, domain-specific innovativeness was expected to influence new product adoption behavior. However, as the estimation results show that domain-specific innovativeness has no effect on new product adoption behavior $(\beta=.07$, $p=.869)$, Hypothesis 3 is rejected. Finally, online opinion leadership was expected to influence new product adoption behavior. Here, the estimation results show that the path from online opinion leadership to new product adoption behavior ( $\beta=1.25 p=.008$ ) is positive and significant at the .05 level. Thus, Hypothesis 4 is supported. The estimation results are shown in Figure 3, along with the standardized estimates, t-values, and significance probabilities.

\subsection{Indirect Effects}

The next step was to examine whether indirect effects exist for the constructs. Following Preacher and Hayes (2008), we used a bootstrapping estimation to test mediation effects (with bootstrap sample size of 1000 , confidence interval of 95\%). The bootstrapping estimation results indeed confirmed that stimulation has an indirect effect through domain-specific consumer innovativeness on online opinion leadership (effect size $=.10$, LLCI $=.02$, ULCI $=.17$ ), while neither hedonism (effect size $=.06$, LLCI $=-.02$, ULCI $=.16$ ) nor achievement $($ effect size $=.04$, LLCI $=-.03$, ULCI $=.15$ ) has an indirect effect on online opinion leadership through consumer innovativeness. In addition, domain-specific innovativeness does not directly influence new product adoption behavior (effect size $=-.05$, LLCI $=-.72$, ULCI $=.63)$ consistent with the result from

〈Figure 3〉 Estimation Results for the Direct Effects

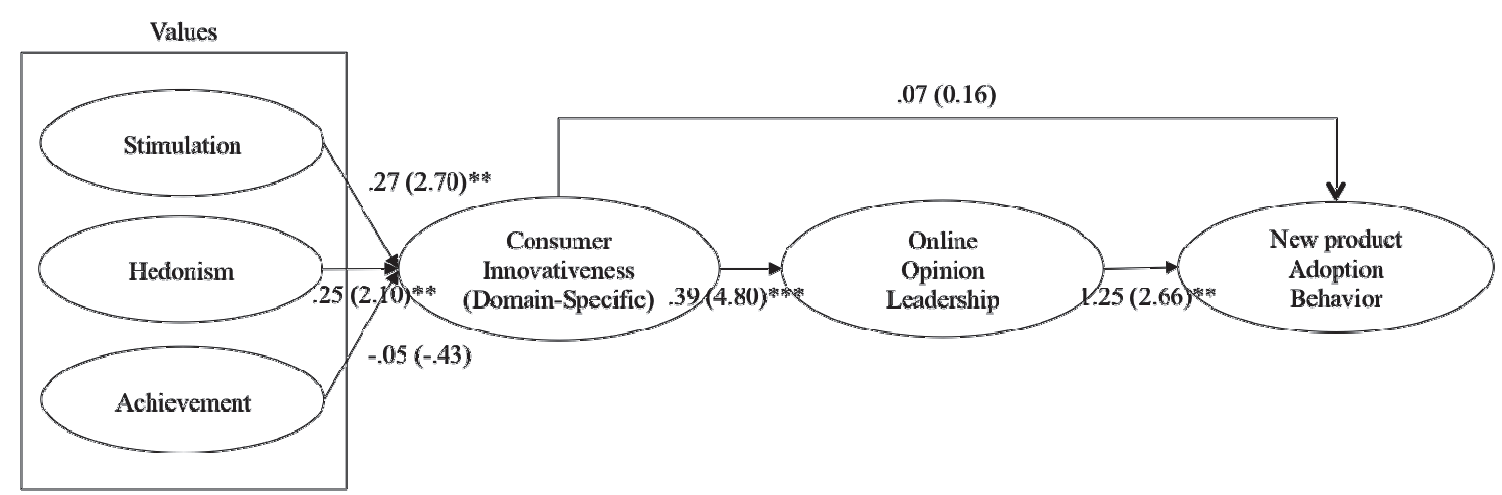


structural equation modeling, but does indirectly influence new product adoption behavior through online opinion leadership, as expected (effect size $=.44$, LLCI $=.08$, ULCI $=.93)$. Hence, we confirmed that domain-specific innovativeness positively affects new product adoption behavior, mediated through online opinion leadership.

\section{Discussion}

This study examined the links between values, consumer innovativeness, online opinion leadership, and new product adoption behavior. As the new product category, we chose wearable technology. The Schwartz Values Scale (Schwartz 1992) was used to unveil which value types affect consumers' innovative characteristics and their online opinion leadership, which shed new light on precisely how consumer innovativeness and online opinion leadership affect consumers' new product adoption behavior. As the results show, consumers who value stimulation and hedonism as guiding principles in their lives are more likely to be innovative, and these innovative consumers are more likely to assume roles as online opinion leaders. These online opinion leaders are again more likely to adopt new products faster than others. The mediating effect of consumer innovativeness between the value of stimulation and online opinion leadership, as well as the mediating effect of online opinion leadership between consumer innovativeness and new product adoption behavior were confirmed.

The positive significant direct effects of stimulation and hedonism on consumer innovativeness suggest that researchers and marketers should focus on consumers who maintain lifestyles built around these two types of values when tasked with disseminating information on new products. The results of this study are in agreement with those reported by previous researchers investigating the relationships between the value stimulation and consumer innovativeness (Steenkamp \& Baumgartner 1992; Steenkamp, Hofstede \& Wedel 1999) and between the value hedonism and innovative characteristics of consumers (Cho \& Workman 2011; Goldsmith, Heitmeyer \& Freiden 1991). The results of the current study also reinforce the validity of the Schwartz Values Scale (Schwartz 1992) in that its value measuring openness to change - stimulation - indeed proved useful in the context of innovativeness research and opinion leadership research. In this regard, this study extends the usefulness of the Schwartz Values Scale to the domain of new product adoption behavior research.

Marketers can identify those consumers who value stimulation and hedonism in their lives as the ones who are likely to possess stronger consumer innovativeness. These consumers are more likely to be online opinion leaders, who would buy new products in early stage of product 
launch. This suggests that the marketers of wearable technology should incorporate elements of stimulation and hedonism into their marketing communication materials in order to enhance online opinion leadership that eventually leads to new product adoption behavior. For example, introducing photos and videos of celebrities who are not only seeking exciting activities and adventures, but also enjoying pleasant lives while wearing wearable watches or bands may be an effective approach. For example, the advertising campaign conducted by the Samsung Russia marketing team on Instagram showed models wearing Samsung gear series while kayaking, biking, and indulging in coffee breaks. Images such as these that incorporate the two target values - stimulation and hedonism - will be far more likely to appeal to potential innovators and online opinion leaders than static photos that only depict the product itself. Recently, it has become easier for the companies to showcase their wearable watches or bands worn by celebrities enjoying stimulating and hedonic activities, due to the increasing popularity of videos in social media. For instance, Instagram not only introduced a new function called "stories" where people can share their live videos in real time, but also promoted their business customers to use this function for advertising products and services. Companies may benefit from taking this new feature as it helps marketers identify target consumers with stimulation and hedonism tendency, who will help promote their products thorough online opinion leadership.

In addition, managers will benefit from planning and implementing co-branding strategy that helps consumers perceive different values permeated into their lives from the co-branded product. In particular, co-branding through active collaboration between multiple brands that can bring the value of stimulation and hedonism to consumers may be a viable strategy to motivate consumers to purchase new products through consumer innovativeness and opinion leadership. For example, Apple Watch Nike Plus, a wearable watch launched by Apple along with the leading sport brand Nike, is a wise creation in that the product is desired by consumers who pursue stimulation and hedonism through outdoor activities. According to Chuah et al. (2016), wearable watches should fulfill both functional and hedonic needs of users because they contain both technology and fashion components. In order to address the stimulation and hedonism values, it is suggested that managers can collaborate with popular luxury brands (e.g., Louis Vuitton, Goyard, etc.) that are actively promoting customization for stimulation and hedonism.

Consistent with Rogers' (1995) innovation diffusion theory, early adopters of new products appear to be those opinion leaders who persuade others to adopt new products by providing information (Agarwal et al. 1998). In this study, consumers with domain-specific innovativeness 
possessed a higher level of online opinion leadership. Furthermore, this study also revealed that consumers who possess a higher level of online opinion leadership will also have the inclination to adopt new products faster than others. These results are congruent with the findings of prior research exploring the relationship between innovativeness and opinion leadership (Grewal, Mehta \& Kardes 2000; Janjua \& Shahjahan 2015; Lyons \& Henderson 2005; Ruvio \& Shoham 2007) and the relationship between opinion leadership and new product adoption behavior (Childers 1986; Flynn, Goldsmith \& Eastman 1996; Goldsmith \& De Witt 2003). This study not only extends Rogers' innovation diffusion theory (1995), but also the abovementioned existing research streams in that it extends the relationships to the online context by adapting the existing measurements used for measuring opinion leadership (Huddleston, Ford \& Bickle 1993).

In addition to these direct effects, the indirect effects between the constructs were also explored in this study. Interestingly, domainspecific innovativeness had no direct influence on new product adoption behavior, however it did have an indirect effect. This suggests that consumers' innovativeness for a certain product category does not directly lead to the adoption of new products, but rather indirectly leads to the adoption through online opinion leadership. This finding emphasizes the importance of online opinion leadership as a mediator between consumer innovativeness and new product adoption behavior.

The value achievement did not affect consumer innovativeness in the current study. Nor did it have indirect effects on online opinion leadership. Hence, at least for wearable devices, these findings do not support Rogers' (1983) argument that early adopters tend to be higher in achievement motivation (as cited in Steenkamp, Hofstede \& Wedel 1999, p. 56). Instead, these empirical results clarify the insignificant relationship between "resultant self-enhancement (i.e., the importance attached to self-enhancement minus the importance attached to self-transcendence; Feather 1995)" and consumer innovativeness found by Steenkamp, Hofstede, and Wedel (1999, p. 58).

\section{Limitations and Conclusions}

As with any study, this study suffers from several limitations. First and foremost, the generalization of the findings across product categories other than wearable technology may be limited. This study utilized the wearable watch/band as the unit of analysis. This type of wearable technology also falls into the electronic product category, where consumers have the propensity to conduct in depth information searches and to be highly involved in making purchasing decisions because of the 
relatively high cost of product acquisition (Im, Bayus \& Mason 2003).

Second, the results may be relatively unstable due to the sheer number of types of wearable device that the participants own, which included diverse types of wearable watch/bands, including the Apple Watch series, the Samsung Gear Series, LG's G Watch Series, the Mi Band series from Xiaomi, and the Fitbit series, among others. Even though half the survey participants used Samsung Gear Series devices, it is very possible that the results could differ depending on the types of wearable watch/ band the participants own. For example, achievement value could have exerted a significant effect on the dependent variables if the majority of the participants had possessed one of the Apple Watch series. To Apple consumers, an Apple product is expected to be a way to express themselves and their lifestyle. Owning a Mac, for instance, represents that they are mainstream, independent thinkers, innovators and the ones who are ahead of the crowd (Kotler et al. 2015). If the majority of participants had been the Apple buyers, such unique consumer characteristics could have affected the results of the study in a different way.

Lastly, other motivational type values among the Schwartz Values Survey (Schwartz 1992) may have significant effects on consumer innovativeness, online opinion leadership, and new product adoption behavior. The current study was restricted to an examination of only three motivational value types, namely stimulation, hedonism, and achievement. In particular, although Schwartz categorized self-direction value as one of the lower order type of values under openness to change (Schwartz 1992), this was not included in this empirical analysis because the sub factor values of the selfdirection value - self respect, choosing own goals, creativity, curious, freedom, independence - appeared to lack convergence in this context. By refining these sub factor values, self-direction value may become a useful part of future research into innovation, opinion leadership, and new product adoption behavior.

〈Received April 28. 2017〉

〈Accepted August 5. 2017〉

\section{References}

Agarwal, Rita, Manju Ahuja, Pamela E. Carter and Mitch Gans (1998). "Early and Late Adopters of IT Innovations: Extensions to Innovation Diffusion Theory. In Proceedings of the DIGIT Conference (pp. 1-18).

Anderson, James C. and David W. Gerbing (1988). "Structural Equation Modeling in Practice: A Review and Recommended Two-step Approach.” Psychological Bulletin, 103(3), 411-423. 
Baumgarten, Steven A. (1975). "The Innovative Communicator in the Diffusion Process." Journal of Marketing Research, 12(1), 12-18.

Berger, Jonah and Raghuram Iyengar (2013). "Communication Channels and Word of Mouth: How the Medium Shapes the Message." Journal of Consumer Research, 40(3), 567-579.

Childers, Terry L. (1986). "Assessment of the Psychometric Properties of an Opinion Leadership Scale." Journal of Marketing Research, 23(2), 184-188.

Cho, Siwon and Jane Workman (2011). "Gender, Fashion Innovativeness and Opinion Leadership, and Need for Touch: Effects on Multi-channel Choice and Touch/Nontouch Preference in Clothing Shopping." Journal of Fashion Marketing and Management: An International Journal, 15(3), 363-382.

Chuah, Stephanie Hui-Wen, Philipp A. Rauschnabel, Nina Krey, Bang Nguyen, Thurasamy Ramayah and Shwetak Lade (2016). "Wearable technologies: The role of usefulness and visibility in smartwatch adoption." Computers in Human Behavior, 65, 276-284.

Dellarocas, Chrysanthos (2003). “The Digitization of Word of Mouth: Promise and Challenges of Online Feedback Mechanisms." Management Science, 49(10), 1407-1424. Feather, Norman T. (1995). "Values, Valences, and Choice: The Influence of Values on the Perceived Attractiveness and Choice of Alternatives." Journal of Personality and Social Psychology, 68(6), 1135-1151. Flynn, Leisa Reinecke, Ronald E. Goldsmith and Jacqueline K. Eastman (1996). "Opinion Leaders and Opinion Seekers: Two New Measurement Scales." Journal of the Academy of Marketing Science, 24(2), 137-147.

Gatignon, Hubert and Thomas S. Robertson (1985). "A Propositional Inventory for New Diffusion Research." Journal of Consumer Research, 11(4), 849-867.

Goldsmith, Ronald E. and Thomas S. De Witt (2003). "The Predictive Validity of an Opinion Leadership Scale." Journal of Marketing Theory and Practice, 11(1), 28-35. and Jon B. Freiden (1995). "The Generality/Specificity Issue in Consumer Innovativeness Research." Technovation, 15(10), 601-612. Jeanne, R. Heitmeyer and Jon B. Freiden (1991). "Social Values and Fashion Leadership." Clothing and Textiles Research Journal, 10(1), 37-45. and Charles Hofacker (1991). "Measuring Consumer Innovativeness." Journal of the Academy of Marketing Science, 19(3), 209-221.

Grewal, Rajdeep, Raj Mehta and Frank R. Kardes (2000). "The Role of the Social- 
identity Function of Attitudes in Consumer Innovativeness and Opinion Leadership. Journal of Economic Psychology, 21(3), 233-252.

Hair, Joseph F., Ronald L. Tatham, Rolph E. Anderson and William Black (1998). Multivariate Data Analysis (5 ${ }^{\text {th }}$ Edn.) New York: Prentice Hall.

Hennig-Thurau, Thorsten, Kevin P. Gwinner, Gianfranco Walsh and Dwayne D. Gremler (2004). "Electronic Word-of-Mouth via Consumer-Opinion Platforms: What Motivates Consumers to Articulate Themselves on the Internet?" Journal of Interactive Marketing, 18(1), 38-52.

Hirschman, Elizabeth C. (1980). "Innovativeness, Novelty Seeking, and Consumer Creativity." Journal of Consumer Research, 7(3), 283295.

Homer, Pamela Miles and Lynne R. Kahle (1988). "A structural Equation Test of the Value-Attitude-Behavior Hierarchy." Journal of Personality and Social Psychology, 54 (4), 638-646.

Huddleston, Patricia, Imogene Ford and Marianne C. Bickle (1993). "Demographic and Lifestyle Characteristics as Predictors of Fashion Opinion Leadership Among Mature Consumers." Clothing and Textiles Research Journal, 11(4), 26-31.

Hunter, M. Gordon (Ed.) (2010). Technological Advancement in Developed and Developing Countries: Discoveries in Global Information
Management: Discoveries in Global Information Management. Hershey, PA, USA: IGI Global.

Im, Subin, Barry L. Bayus and Charlotte H. Mason (2003). "An Empirical Study of Innate Consumer Innovativeness, Personal Characteristics, and New-Product Adoption Behavior." Journal of the Academy of Marketing Science, 31(1), 61-73.

Iyengar, Raghuram, Christophe Van den Bulte and Thomas W. Valente (2011). "Opinion Leadership and Social Contagion in New Product Diffusion." Marketing Science, 30 (2), 195-212.

Janjua, Qaiser and Shirza Shahjahan (2015). "Analysing Factors Affecting Consumer Innovativeness in Fashion Clothing and the Influence of Morning TV Shows." International Journal of Fashion Design, Technology and Education, 8(3), 268-276. Jellicorse, Robert W. (2015). “2015-2016 Pebble Smartwatch Advertising Campaign." University of Tennessee Honors Thesis, (accessed March 10, 2017), [available at http://trace.tennessee.edu/utk_chanhonoproj /1867].

Kahle, Lynn R. (1983). Social Values and Social Change: Adaptation to Life in America. New York: Praeger.

Kamakura, Wagner A. and José Afonso Mazzon (1991). "Value Segmentation: A Model for the Measurement of Values and Value Systems." Journal of Consumer Research, 
18(2), 208-218.

Kark, Ronit and Dina Van Dijk (2007). "Motivation to Lead, Motivation to Follow: The Role of the Self-Regulatory Focus in Leadership Processes." Academy of Management Review, 32(2), 500-528.

Katz, Elihu and Paul Felix Lazarsfeld (1955). Personal Influence: The Part Played by People in the Flow of Mass Communications. New York: The Free Press.

King, Charles W. and John O. Summers (1970).

"Overlap of Opinion Leadership across Consumer Product Categories." Journal of Marketing Research, 7(1), 43-50.

Kotler, Philip and Gerald Zaltman (1976). "Targeting Prospects for a New Product." Journal of Advertising Research, 16, 7-20. , Philip, Suzan Burton, Kenneth Deans, Linen Brown and Gary Armstrong (2015), Marketing. AU: Pearson Higher Education. Lyons, Barbara and Kenneth Henderson (2005).

"Opinion Leadership in a ComputerMediated Environment." Journal of Consumer Behaviour, 4(5), 319-329.

Madrigal, Robert and Lynn R. Kahle (1994). "Predicting Vacation Activity Preferences on the Basis of Value-System Segmentation." Journal of Travel Research, 32(3), 22-28. Midgley, David F. and Grahame R. Dowling (1978). "Innovativeness: The Concept and Its Measurement." Journal of Consumer Research, 4(4), 229-242. and Grahame R. Dowling (1993). “A
Longitudinal Study of Product Form Innovation: The Interaction Between Predispositions and Social Messages." Journal of Consumer Research, 19(4), 611-625.

Myers, James H. and Thomas S. Robertson (1972). "Dimensions of Opinion Leadership." Journal of Marketing Research, 9(1), 41-46. Park, Chang Sup (2013). “Does Twitter Motivate Involvement in Politics? Tweeting, Opinion Leadership, and Political Engagement." Computers in Human Behavior, 29(4), 1641-1648.

Peck, Joann and Terry L. Childers (2003). "Individual Differences in Haptic Information Processing: The "Need for Touch" Scale. Journal of Consumer Research, 30(3), 430-442.

Preacher, Kristopher J. and Andrew F. Hayes (2008). “Asymptotic and Resampling Strategies for Assessing and Comparing Indirect Effects in Multiple Mediator Models." Behavior Research Methods, 40 (3), 879-891.

Rogers, Everett M. (1983). Diffusion of innovations ( ${ }^{\text {rd }}$ Edn.) New York: Free Press.

(1995). "Chapter 2. Diffusion of Innovations: Modifications of a Model for Telecommunications." In Die Diffusion von Innovationen in der Telekommunikation, Volume 17 of the series Schriftenreihe des Wissenschaftlichen Instituts für Kommunikationsdienste, New York, 
Springer, 25-38.

(2002). "Diffusion of Preventive Innovations." Addictive Behaviors, 27(6), 989-993.

(2003). "Chapter 5. Diffusion Networks."

In Networks in the Knowledge Economy, Robert L. Cross, Andrew Parker and Lisa Sasson, eds., New York, Oxford University Press, 130-179.

and F. Floyd Shoemaker (1971).

Communication of Innovations: A Cross-

Cultural Approach. New York: Free Press.

Ruvio, Ayalla and Aviv Shoham (2007). "Innovativeness, Exploratory Behavior, Market Mavenship, and Opinion Leadership: An Empirical Examination in the Asian Context." Psychology and Marketing, 24 (8), 703-722.

Schäfer, Mike S. and Monika Taddicken (2015). "Opinion Leadership Revisited: A Classical Concept in a Changing Media Environment." International Journal of Communication, 9, 956-959.

Schwartz, Shalom H. (1992). "Universals in the Content and Structure of Values: Theoretical Advances and Empirical Tests in 20 Countries." Advances in Experimental Social Psychology, 25, 1-65.

(1996). "Value Priorities and Behavior: Applying a Theory of Integrated Value Systems in the Psychology of Values," in The Ontario Symposium: Vol. 8. The Psychology of Values, C. Seligman, J. M.
Olson and M. P. Zanna, eds. Mahwah, NJ: Lawrence Erlbaum.

Shah, Dhavan V. and Dietram A. Scheufele (2006). "Explicating Opinion Leadership: Nonpolitical Dispositions, Information Consumption, and Civic Participation." Political Communication, 23(1), 1-22.

Steenkamp, Jan-Benedict E. M. and Hans Baumgartner (1992). “The Role of Optimum Stimulation Level in Exploratory Consumer Behavior." Journal of Consumer Research, 19(3), 434-448.

. Frenkel ter Hofstede and Michel Wedel (1999). "A Cross-National Investigation into the Individual and National Cultural Antecedents of Consumer Innovativeness." The Journal of Marketing, 63(2), 55-69. Summers, John O. (1970). "The Identity of Women's Clothing Fashion Opinion Leaders." Journal of Marketing Research, 7(2), 178185.

Sun, Tao, Seounmi Youn, Guohua Wu and Mana Kuntaraporn (2006). "Online Wordof-Mouth (or Mouse): An Exploration of Its Antecedents and Consequences." Journal of Computer-Mediated Communication, 11(4), 1104-1127.

Vernette, Éric (2004). “Targeting Women's Clothing Fashion Opinion Leaders in Media Planning: An Application for Magazines." Journal of Advertising Research, 44(1), 90-107.

Villanueva, Julian, Shijin Yoo and Dominique 
M. Hanssens (2008). "The Impact of Marketing-Induced Versus Word-of-Mouth Customer Acquisition on Customer Equity Growth." Journal of Marketing Research, 45(1), 48-59.

Vraga, Emily K., Ashley A. Anderson, John E. Kotcher and Edward W. Maibach (2015). "Issue-Specific Engagement: How Facebook Contributes to Opinion Leadership and
Efficacy on Energy and Climate Issues." Journal of Information Technology \& Politics, 12(2), 200-218.

Williams, Robin M., Jr. (1979). "Chapter 2. Change and Stability in Values and Value Systems: A Sociological Perspective," in Understanding Human Values: Individual and Societal, Milton Rokeach, ed. New York: The Free Press, 15-46. 


\section{〈Appendix〉 Measurement Items}

\begin{tabular}{|c|c|c|c|}
\hline Construct & Measures & Scale & Adapted from \\
\hline \multirow{3}{*}{$\begin{array}{c}\text { Stimulation } \\
\text { (Cronbach's } \alpha=0.867)\end{array}$} & varied life filled with challenge & 7-point Likert scale: & \multirow{3}{*}{ Schwartz (1992) } \\
\hline & varied life filled with change & $1=$ not important at all; & \\
\hline & daring & $7=$ extremely important. & \\
\hline \multirow{3}{*}{$\begin{array}{c}\text { Hedonism } \\
\text { (Cronbach's } \alpha=0.796)\end{array}$} & pleasure & 7-point Likert scale: & \multirow{3}{*}{ Schwartz (1992) } \\
\hline & joy & $1=$ not important at all; & \\
\hline & gratification of desires & $7=$ extremely important. & \\
\hline \multirow{3}{*}{$\begin{array}{c}\text { Achievement } \\
(\text { Cronbach's } \alpha=0.83)\end{array}$} & capable & 7-point Likert scale: & \multirow{3}{*}{ Schwartz (1992) } \\
\hline & influential & $1=$ not important at all; & \\
\hline & intelligent & 7 = extremely important. & \\
\hline $\begin{array}{c}\text { Domain-specific } \\
\text { Innovativeness } \\
\text { (Cronhach's } \alpha=0.796)\end{array}$ & $\begin{array}{l}\text { I know the names of new wearable devices before other people do. } \\
\text { If I heard that a new wearable device was available in the store, I would be interested } \\
\text { enough to buy it. } \\
\text { I will buy a new wearable device even if I have not seen it before. }\end{array}$ & $\begin{array}{l}\text { 7-point Likert scale: } \\
\text { 1= strongly disagree; } \\
7=\text { strongly agree. }\end{array}$ & $\begin{array}{l}\text { Goldsmith, Freiden \& Eastman } \\
\text { (1995) }\end{array}$ \\
\hline $\begin{array}{l}\text { Online Opinion Leadership } \\
\quad(\text { Cronbach's } \alpha=0.856)\end{array}$ & $\begin{array}{l}\text { I believe my online media (Facebook, Instagram, Blog, etc) page is a very good source } \\
\text { of information about wearable devices. } \\
\text { In a discussion of wearable devices on online media (Facebook, Instagram, Blog, etc), } \\
\text { it happens most that I tell my friends about them. } \\
\text { I like to help others make decisions about wearable devices through online media } \\
\text { (Facebook, Instagram, Blog, etc). } \\
\text { In general, I often talk with my online media (Facebook, Instagram, Blog, etc) friends } \\
\text { about wearable devices. }\end{array}$ & $\begin{array}{l}\text { 7-point Likert scale: } \\
\text { 1= strongly disagree; } \\
7=\text { strongly agree. }\end{array}$ & $\begin{array}{l}\text { Huddleston, Ford \& Bickle } \\
\text { (1993) }\end{array}$ \\
\hline
\end{tabular}

